Syaiful Zuhri Harahap ${ }^{1}$, Amelia Nastuti ${ }^{2}$ Informatika : Jurnal Ilmiah Fakultas Sains dan Teknologi,

Universitas Labuhanbatu

Vol.7 No.3/September/2019

2615-1855 (E-ISSN)

2303-2863 (P-ISSN)

\title{
TEKNIK DATA MINING UNTUK PENENTUAN PAKET HEMAT SEMBAKO DAN KEBUTUHAN HARIAN DENGAN MENGGUNAKAN ALGORITMA FP-GROWTH (STUDI KASUS DI ULFAMART LUBUK ALUNG)
}

\author{
Syaiful Zuhri Harahap ${ }^{1}$ \\ Fakultas Sains dan Teknologi, Universitas Labuhanbatu \\ Email: syaifulzuhriharahap@gmail.com \\ Amelia Nastuti ${ }^{2}$ \\ Universitas Putra Indonesia YPTK Padang \\ Email: amelianas2310@gmail.com
}

\begin{abstract}
Abstrak
Dalam sebuah bisnis, diperlukan upaya memaksimalkan keuntungan.Diantaranya dengan melakukan promosi.Minimarket Ulfamart belum melakukan inovasi berupa promosi paket hemat kepada pelanggan.Ketepatan promosi dapat dipelajari dari database sebuah perusahaan ritel utamanya pola belanja pada produk yang biasa dibeli bersamaan. Informasi tentang pola belanja pelanggan yang tidak akurat menyebabkan kebijakan promosi tidak tepat dan efisien.Salah satu upaya lazim untuk memperoleh dan menggali pola belanja pelanggan adalah menggunakan data mining yang dikenal sebagai Knowledge Discovery in Database(KDD).Salah satu teknik data mining adalah Association Rule yang merupakan prosedur dalam Market Basket Analysis. Market basket didefinisikan sebagai suatu itemset yang dibeli secara bersamaan oleh pelanggan dalam suatu transaksi.Market basket analysis adalah suatu alat yang ampuh untuk strategi cross-selling. Suatu pola ditentukan oleh dua parameter, yaitu support (nilai penunjang) dan confidence (nilai kepastian).Algoritma Frequent Pattern Growth (FP-Growth) digunakan untuk membantu menemukan sejumlah aturan asosiasi dari basis data dengan menerapkan struktur data Tree atau disebut dengan FP-Tree.Implementasi menggunakan RapidMiner untuk membantu menemukan pola yang akurat sehingga didapatkan kombinasi item yang dapat dijadikan sebuah pakethemat.
\end{abstract}

Kata kunci :data mining, aturan asosiasi, fp-growth, fp-tree, analisis keranjang belanja

\begin{abstract}
In a business, it takes effort to maximize profits. Among them by doing promotions. Minimarket Ulfamart has not done innovation in the form of promotion of frugal packages to customers. The precision of promotion can be learned from the database of a retail company primarily shopping patterns on products commonly purchased simultaneously. Information about inaccurate customer spending patterns results in inaccurate and efficient promotional policies. One of the most common attempts to acquire and explore customer spending patterns is to use data mining known as Knowledge Discovery in Database (KDD). One of the data mining techniques is the Association Rule which is a procedure in Market Basket Analysis. Market basketball is defined as an itemset purchased simultaneously by the customer in a transaction. Market basket analysis is a powerful tool for cross-selling strategies. A pattern is determined by two parameters, namely support (value of support) and confidence (value of certainty). The Frequent Pattern Growth (FP-Growth) algorithm is used to help find some association rules from the database by applying a Tree Tree structure or called FP-Tree. Implementation using RapidMiner to help find accurate patterns to get a combination of items that can be used as a frugal package.
\end{abstract}

Keywords: data mining, association rule mining, fp-growth,fp-tree,market basket analysis. 


\section{I.PENDAHULUAN}

Pertumbuhan kegiatan jual-beli di Indonesia tercermin dengan pesatnya pertumbuhan minimarket sebagai salah satu pasar modern dan pasokan baru di Indonesia.Bisnis minimarket saat ini mengalami perkembangan pesat apalagi dengan menggunakan sistem yang lebih modern memudahkan dalam penghitungan sehingga dapat mengimbangi kebutuhan masyarakat yang tinggi. Minimarket menawarkan konsep recreational shopping atau wisata belanja yang tidak jauh dari rumah sehingga pembeli tidak perlu repot

jauh - jauh untuk berbelanja. Studi kasusyang diangkat pada penelitian ini adalah minimarket Ulfamart yang beralamat di Jl. Padang - Bukittinggi KM 37, Lubuk Alung.Minimarket ini menjual berbagai macam kebutuhan layaknya toko retail pada umumnya, termasuk kebutuhan sembako.Pembeli yang rata-rata ibu rumah tangga ingin membeli beberapa sembako sekaligus kebutuhan harian dengan harga yang murah.Minimarket Ulfamart belum pernah mengeluarkan atau menjualkan produk dalam bentuk paket hemat.

Salah satu cara yang dapat diterapkan untuk menggali informasi adalah dengan menerapkan penggunaan Data Mining. Data mining adalah suatu proses menemukan hubungan yang berarti, pola, dan kecenderungan dengan memeriksa dalam sekumpulan besar data yang tersimpan dalam penyimpanan dengan menggunakan teknik pengenalan pola seperti teknik statistik dan matematika [1]. Association rule mining merupakan cara terbaik untuk memberikan dukungan keputusan ilmiah pada pasar retail melalui hubungan mining association antara barang yang telah dibeli secarabersama-sama. Penemuan dari hubungan ini dapat membantu pedagang untuk mengembangkan strategi penjualan dengan mempertimbangkan barang yang sering dibeli bersama oleh pelanggan, hal ini sangat penting karena dapat membanturekomendasi produk yang dapat dikombinasikan menjadi sebuah paket.Banyak algoritma yang diusulkan untuk menemukan pola asosiasi. Adapun dalam penelitian ini akan dibahas bagaimana cara mengimplementasikan salah satu algoritma dalam Data Mining, yaitu algoritma frequent Pattern-Growth (FP-Growth). Algoritma ini memampatkan kumpulan data sebuah $F P$ tree, memindai database dua kali, tidak menghasilkanitem kandidat dalam proses penambangan, dan sangat efisien untuk penambangan [2].

Penelitian tentang penerapan aturan asosiasi menggunakan Algoritma FPGrowthtelah dilakukan oleh Goldie \& Dana (2012) membahas tentang market basket analysis terhadap data penjualan produkbuku dengan algortima apriori dan FP- Growth , penelitian lain oleh Fitriyani (2015) mengimplementasikan algoritma fp- growth menggunakan association rule pada market basket analysis, ghozali dkk (2017 menganalisa pola belanja dengan algoritma FP-Growth. Penelitian kali ini diharapkan memberikan nilai lebih berupa kemudahan bagi pengelola minimarket dalam menentukan produk yang dapat digabungkan menjadi sebuah paket sebagai bentuk inovasi baru dalam hal promosi.

\section{LANDASAN TEORI}

Knowledge Discovery in Database(KDD)

Knowlegde Discovery in Database melibatkan hasil proses Data Mining (proses pengekstrak kecenderungan suatu pola data), kemudian mengubah hasilnya secara akurat menjadi informasi yang mudah dipahami [3]. Proses KDD secara garis besar dapat dijelaskan sebagai berikut :

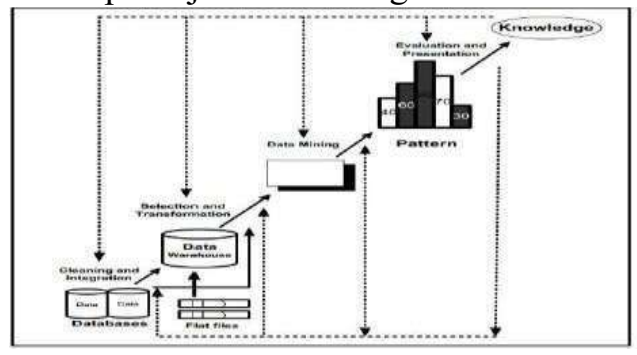

Gambar 1.Proses Knowledge discoveryin database. 
Tahapan proses KDD ada 5 (Irwan Budiman, 2012), yaitu:

1) Data Selection

Pemilihan data dari sekumpulan operasional perlu dilakukan sebelum taha penggalian informasi dalam KDD dimulai.

\section{2) Preprocessing}

Sebelum proses

dilaksanakan,perlu dilakukan proses cleaning

dengan tujuan untuk membuang duplikasi

data, memeriksa data yang inkonsisten, dan

memperbaiki kesalahan pada data, seperti kesalahan cetak. Juga dilakukan proses enrichment, yaitu proses "memperkaya" data yang sudah ada dengan data atau informasi lain yang relevan dan diperlukan untuk KDD, seperti data atau informasi eksternal.

3) Transformation

Yaitu proses coding pada data yang telah dipilih, sehingga data tersebut sesuai untuk proses data mining. Proses coding dalam KDD merupakan proses kreatif dan dangat
tergantung pada jenis atau pola informasi yang akan dicari dalam database.

\section{4) Data Mining}

Proses mencari pola atau informasi menarik dalam data terpilih dengan

menggunakan teknik atau metode tertentu.

\section{5) Interpretation / Evaluation}

Pola informasi yang dihasilkan dari proses

data mining perlu

ditampilkan dalam bentuk yang

mudah dimengerti oleh pihak berkepentingan. Tahap ini merupakana bagian dari proses

KDD yang disebut dengan interpretation. Tahap ini mencakup pemeriksaan apakah pola atau informasi yang ditemukan bertentangan dengan fakta atau hipotesa yang ada sebelumnya atau tidak.

Data Mining digunakan untuk ekstraksi informasi penting yang tersembunyi dari dataset yang besar. Dengan adanya Data Mining maka akan didapatkan suatu permata ta berupa pengetahuan di dalam kumpulan data data yang banyak jumlahnya [5].

\section{METODE PENELITIAN}

Fp-Growth
Algoritma
FP-Growth
merupakan

pengembangan dari algoritma

Apriori.Sehingga kekurangan dari algoritma Apriori diperbaiki oleh algoritma FPGrowth.Frequent Pattern Growth (FP- Growth) adalah salah satu alternatif algoritma yang dapat digunakan untuk menentukan himpunan data yang paling sering muncul (frequent itemset) dalam sebuah kumpulan data. Pada algoritma Apriori diperlukan generate candidate untuk mendapatkan frequent itemsets. Akan tetapi, di algoritma FP-Growth generate candidate tidak dilakukan karena FPGrowth menggunakan konsep pembangunan tree dalam pencarian frequent itemsets. Hal tersebutlah yang menyebabkan algoritma FPGrowth lebih cepat dari algoritma Apriori [6].

Untuk menentukan frequent itemset pada data transaksi tersebut, dapat dilakukan langkah-langkah berikut ini:

1. Menentukan Minimum Support.

2. Menentukan Header Frequent Itemset

3. Membuat FP-Tree

4. Membuat Conditional Pattern berdasarkan FP-Tree

yang 5. Menentukan Frequent Item-set

Penelitian ini melakukan tahapan dari analisa mulai dari data secara keseluruhan serta proses manual pembahasan dari pengolahan data yang akan dilakukan asosiasi menggunakan pemodelan FP-growth berdasarkan kerangka kerja penelitian yang terdapat pada bab III Metotologi Penelitian. Secara garis besar tahapan dari proses analisa dan pembahasan pada bab ini dapat digambarkan dalam bagan alir sebagai berikut: 


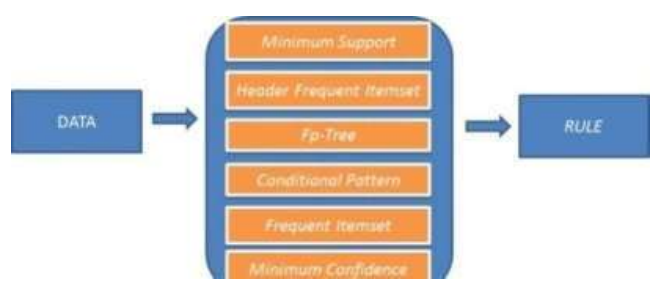

Gambar 2. Bagan Alir Tahapan Analisa da Perancangan

\section{HASIL DAN PEMBAHASAN}

Data yang digunakan untuk pengolahan data ini adalah data terakhir yang sudah dilakukan proses pembersihan data. Dalam tahap ini akan dilakukan penyelesaian masalah pada perekomendasian paket produk di minimarket Ulfamart dengan metode Association Rule menggunakan Algoritma FP-Growth .

Berdasarkan tujuan bisnis pada minimarket Ulfamart data yang digunakan dalam penelitian ini adalah laporan transaksi penjualan produk sembako dan kebutuhan harian pada bulan Juni 2017 sampai dengan Agustus 2017 yang berasal dari database file (dbf). Atribut yang terdapat pada laporan transaksi penjualan terdiri dari:

1. Notrans

2. Barcode

3. Waktu

4. Uraian

5. Kty

6. Jumlah

7. Total

8. Bayar

9. Kembalian

Persiapan data adalah hal yang harus dilakukan, karena tidak semua atribut digunakan dalam proses data mining. Proses ini dilakukan agar data yang akan digunakan sesuai dengan kebutuhan. Adapun tahapan tahapan preprocessing adalah sebagai berikut:

1. Ekstrasi data
Ekstrasi data adalah proses pengambilan data dari sumber data dalam rangka untuk melanjutkan proses pengolahan data. Dalam penelitian ini data diambil dari file dbf. Data yang digunakan adalah data transaksi penjualan.

2. Pemilihan atribut

Pemilihan atribut adalah proses pemilihan atribut data yang digunakan, sehingga data tersebut dapat diproses sesuai dengan kebutuhan data mining. Dalam tahap ini atribut yang digunakan adalah Faktur dan Kode_item. Faktur merupakan identitas dari setiap transaksi, sedangkan Kode_item digunakan untuk mengetahui jenis barang apa saja yang dibeli oleh pelanggan.

3. Pembersihan data

Proses menghilangkan noise dan menghilangkan data yang tidak relevan disebut pembersihan data. Dari \pm 1.000 total jumlah transaksi mentah, dilakukan proses cleaning data agar didapatkan data yang sesuai dengan kebutuhan penggalian informasi sebanyak 15 transaksi yang merupakan item produk sembako dan kebutuhan harian. Sampel transaksi penjualan pada Minimarket Ulfamart disajikan pada tabel 1 berikut.

Tabel 1. Sampel Transaksi Penjual

\begin{tabular}{|c|c|}
\hline Transak & Item yang Terjual \\
\hline TR01 & Gula Biasa $1 \mathrm{~kg}$, Kopi Mak Angah \\
\hline TR02 & $\begin{array}{l}\text { Beras Solok } 5 \mathrm{~kg} \text {, Indomie Realmeat } \\
\text { Beef, }\end{array}$ \\
\hline TR03 & Mila Tepung Terigu $1 \mathrm{~kg}$, Gula Biasa \\
\hline TR04 & $\begin{array}{l}\text { Okey Sosis Ayam 1.000gram, Kraft } \\
\text { Cheddar } 180 \mathrm{~g}, \text { Kobe Bumbu Instan } 12 \mathrm{~g} \\
\text { Ori }\end{array}$ \\
\hline TR05 & Beras Solok 5kg, Delima $21 \mathrm{tr}$ \\
\hline TR06 & $\begin{array}{l}\text { Bango Kecap Manis 275ml, Kobe } \\
\text { Bumbu }\end{array}$ \\
\hline TR07 & $\begin{array}{l}\text { Prendjak Teh Celup 30, Gula Biasa 1kg, } \\
\text { Kopi Mak Angah }\end{array}$ \\
\hline TR08 & $\begin{array}{l}\text { Kraft Cheddar } 180 \mathrm{~g} \text {, Frisian Flag } \\
\text { Krimer }\end{array}$ \\
\hline TR09 & $\begin{array}{l}\text { Abc Sambal Asli Btl275ml, Prendjak } \\
\text { Teh }\end{array}$ \\
\hline TR10 & Prendjak Teh Celup 30, Gula Biasa $1 \mathrm{~kg}$ \\
\hline TR11 & $\begin{array}{l}\text { Frisian Flag Krimer } 385 \mathrm{gr} \text {, Gula Biasa } \\
1 \mathrm{~kg} \text {, Kopi Mak Angah, Prendjak Teh } \\
\text { Celup } 30\end{array}$ \\
\hline TR12 & $\begin{array}{l}\text { Mila Tepung Terigu } 1 \mathrm{~kg} \text {, Gula Biasa } \\
1 \mathrm{~kg} \text {, }\end{array}$ \\
\hline TR13 & $\begin{array}{l}\text { Mila Tepung Terigu 1kg, Indomie } \\
\text { Realmeat Beef, Sirup ABC Squash }\end{array}$ \\
\hline TR14 & $\begin{array}{l}\text { Frisian Flag Krimer 385gr, Prendjak } \\
\text { Teh }\end{array}$ \\
\hline TR15 & $\begin{array}{l}\text { Bango Kecap Manis } 275 \mathrm{ml} \text {, Kraft } \\
\text { Cheddar } 180 \mathrm{~g}\end{array}$ \\
\hline
\end{tabular}


transaksi pada tabel1 nantinya akan disederhanakan dengan cara menginisialisasi. Setelah item yang terjual pada setiap transaksi disederhanakan, selanjutnya adalah membuat transformasi agar lebih sederhana.Bentuk data dalam bentuk format transactional berdasarkan pada transaksi-transaksi yang ada pada tabel 1 terlihat pada tabel 2 data transactional nya.

Tabel 2. Data Format Transactional

\begin{tabular}{|c|c|c|}
\hline Nama fitem & Inisial & Transaksi \\
\hline Beras solok $5 \mathrm{kj}$ & $A$ & 2 \\
\hline $\begin{array}{l}\text { Mila iepung } \\
\text { terigu } 1 \mathrm{ke}\end{array}$ & B & 3 \\
\hline Gula biass $1 \mathrm{~kg}$ & c & 7 \\
\hline $\begin{array}{l}\text { Kupi muk angah } \\
\text { hecil }\end{array}$ & D & 3 \\
\hline $\begin{array}{l}\text { Prendjak teh } \\
\text { celup } 10\end{array}$ & $\mathrm{E}$ & 5 \\
\hline Delima 21tr & $\mathrm{F}$ & 2 \\
\hline $\begin{array}{l}\text { Inulonnie } \\
\text { realmear hesf }\end{array}$ & G & 2 \\
\hline $\begin{array}{l}\text { Bango kesap } \\
\text { manis } 275 \text { mal }\end{array}$ & $\mathrm{H}$ & 2 \\
\hline $\begin{array}{l}\text { ABC stmbal asli } \\
\text { bt } 1275 \mathrm{ml}\end{array}$ & 1 & 1 \\
\hline $\begin{array}{l}\text { Okay sosis aydm } \\
\text { 1.000yram }\end{array}$ & 1 & 1 \\
\hline $\begin{array}{l}\text { Kruft choddar } \\
\text { 150g }\end{array}$ & $\mathrm{K}$ & 3 \\
\hline $\begin{array}{l}\text { Kobe bumbia } \\
\text { instsa } 12 \mathrm{~g}\end{array}$ & L & 2 \\
\hline $\begin{array}{l}\text { Frisian flagg } \\
\text { krimer 385gr }\end{array}$ & $\mathrm{M}$ & 3 \\
\hline $\begin{array}{l}\text { Provass Kornet } \\
\text { Sipi } 200 \mathrm{gr}\end{array}$ & $\mathrm{N}$ & 0 \\
\hline $\begin{array}{l}\text { Sirden ABC } \\
\text { mackerel }\end{array}$ & o & 0 \\
\hline Bhic hand cuse & $\mathrm{p}$ & 2 \\
\hline Aqua golkon & 0 & 1 \\
\hline $\begin{array}{l}\text { Cuka Dapur } \\
150 \mathrm{mal}\end{array}$ & $R$ & 0 \\
\hline $\begin{array}{l}\text { Otcy nugget } \\
\text { syam L , 000 aram }\end{array}$ & $\mathrm{S}$ & 1 \\
\hline $\begin{array}{l}\text { Sirup ABC } \\
\text { symash jeruk }\end{array}$ & $\mathrm{T}$ & 1 \\
\hline
\end{tabular}

Tahap pemodelan FP-Growth

Pada tahap awal dalam pemodelan adalah menentukan minimum support.Minimum support adalah suatu ukuran yang menunjukan seberapa besar tingkat suatu kombinasi suatu barang pada sebuah data transaksi. Untuk kasus nilai minimum support yang digunakan yaitu $10 \%$ dari 15 data transaksi penjualan yang digunakan yaitu sebesar 1,5 dibulatkan jadi 2, yang berarti barang yang memiliki jumlah frequent kurang dari 2 akan dieliminasi dalam data transaksi. Langkah pertama yang dilakukan untuk menghitung nilai support dari sebuah barang adalah dengan menghitung kemunculan tiap barang yang sudah disusun secara ascending. Jumlah kemunculan setiap barang dapat dilihat pada Tabel 3 .

Tabel 3. Frequent Item

\begin{tabular}{|c|c|}
\hline Kode item & Frequent \\
\hline A & 2 \\
\hline B & 3 \\
\hline C & 7 \\
\hline D & 3 \\
\hline E & 5 \\
\hline F & 2 \\
\hline G & 2 \\
\hline H & 2 \\
\hline I & 1 \\
\hline J & 1 \\
\hline K & 3 \\
\hline L & 2 \\
\hline M & 3 \\
\hline N & 0 \\
\hline O & 0 \\
\hline P & 2 \\
\hline Q & 1 \\
\hline R & 0 \\
\hline S & 1 \\
\hline T & I \\
\hline
\end{tabular}

Setelah mengetahui nilai frequent dari semua item, langkah selanjutnya adalah mengeliminasi item yang tidak memenuhi minimum support yang telah ditentukan. Pada tahap ini item yang memiliki frequent tertinggi akan didahulukan penulisannya. Hasil pengurutan berdasarkan priority dapat dilihat pada Tabel 4. Hasil pengurutan berdasarkan priority berikut ini :

Tabel 4. Hasil Pengurutan Berdasarkan

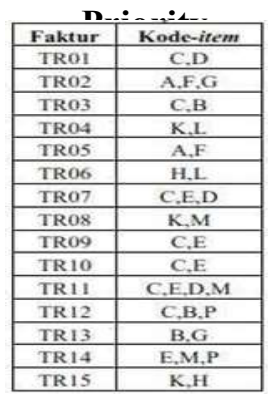


Setelah proses pembacaan faktur TR15 yaitu K,H maka terbentuklah Tree dari semua transaksi yang akan digunakan seperti pada Gambar Hasil pembentukan FP-Tree faktur TR15:

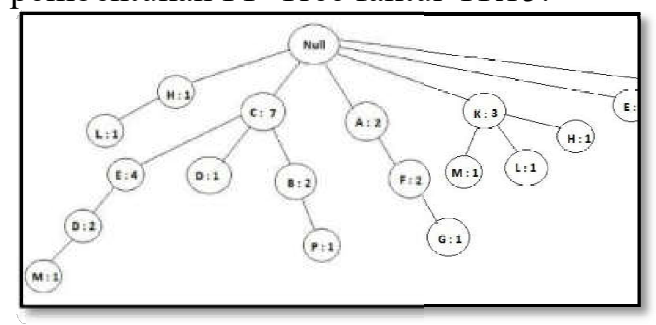

\section{Gambar 3.FP-Tree etelah}

Pembacaan TR15

Pembangkitan conditional pattern base didapatkan melalui hasil FP-Tree seluruhnya, dengan mencari support count terkecil sesuai dengan hasil pengurutan priority. Berikut adalah hasil dari conditional pattern base yang terlihat pada tabel 5 .

Tabel 5. Conditional Pattern Base

\begin{tabular}{|c|c|}
\hline Item & $\begin{array}{l}\text { Conditional Pattern } \\
\text { Base }\end{array}$ \\
\hline $\mathrm{P}$ & $\{\mathrm{C}, \mathrm{B}: 1\}\{\mathrm{E}, \mathrm{M}: 1\}$ \\
\hline L & $\mathrm{AH}: 1\} 3 \mathrm{~K}: \mathrm{H}$ \\
\hline $\mathrm{H}$ & $\mid K=1\}$ \\
\hline G & $\{\mathrm{A}, \mathrm{F}: 1\}\{\mathrm{B}: \mathrm{H}\}$ \\
\hline$F$ & $\{A: 2\}$ \\
\hline $\mathrm{M}$ & $\{C, E, D: 1\}|K: 1|\{E ; 1\}$ \\
\hline $\mathrm{D}$ & $\{C, E: 2\}\{C: 1\}$ \\
\hline $\mathrm{B}$ & $\{\mathrm{C}: 2\}$ \\
\hline $\mathrm{E}$ & $\{C: 4\}$ \\
\hline
\end{tabular}

Pada tahap ini, support count dari setiap item pada setiap conditional pattern base dijumlahkan, lalu setiap item yang memiliki jumlah support count lebih besar atau sama dengan minimum support akan dibangkitkan dengan Conditional FP-Tree.

Conditional FP-Tree untuk kode produk $\mathrm{M}\{\mathrm{E}: 2\}$

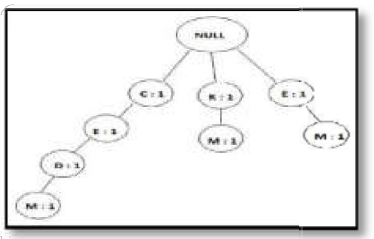

Gambar 4. Conditional FP-Tree
Setelah mendapatkan hasil conditionalFp-Tree, ditemukan beberapa frequent itemset yang keluar seperti pada Tabel 6.Conditional FP-Tree:

Tabel 6.Conditional Fp-Tree

\begin{tabular}{|c|l|}
\hline $\begin{array}{c}\text { Ite } \\
\boldsymbol{m}\end{array}$ & $\begin{array}{l}\text { Conditio } \\
\boldsymbol{n a l} \boldsymbol{F P}- \\
\text { Tree }\end{array}$ \\
\hline $\mathrm{F}$ & $\{\mathrm{A}: 2\}$ \\
\hline $\mathrm{M}$ & $\{\mathrm{E}: 2\}$ \\
\hline $\mathrm{D}$ & $\begin{array}{l}\{\mathrm{C}: 3\} \\
2\}\end{array}$ \\
\hline $\mathrm{B}$ & $\{\mathrm{E}: 2\}$ \\
\hline $\mathrm{E}$ & $\{\mathrm{C}: 4\}$ \\
\hline
\end{tabular}

Setelah mendapatkan hasil Conditional Fp-Tree dari tiap frequent itemset, selanjutnya adalah menentukan suffix dari tiap frequent itemset, seperti pada Tabel 7. Hasil frequent :

Tabel 7. Hasil Frequent Pattern

\begin{tabular}{|c|l|}
\hline $\begin{array}{l}\text { Suf } \\
\text { fix }\end{array}$ & $\begin{array}{l}\text { Freque } \\
\boldsymbol{n t} \\
\text { Pattern }\end{array}$ \\
\hline $\mathrm{F}$ & $\{\mathrm{F}, \mathrm{A}\}$ \\
\hline $\mathrm{M}$ & $\{\mathrm{M}, \mathrm{E}\}$ \\
\hline $\mathrm{D}$ & $\begin{array}{l}\{\mathrm{D}, \mathrm{C}\} \\
\mathrm{D}, \mathrm{E}\}\end{array}$ \\
\hline $\mathrm{B}$ & $\{\mathrm{B}, \mathrm{C}\}$ \\
\hline $\mathrm{E}$ & $\{\mathrm{E}, \mathrm{C}\}$ \\
\hline
\end{tabular}

Dari hasil frequent pattern yang didapatkan, langkah selanjutnya yaitu mencari subset dari masing-masing kode_barang, seperti pada Tabel 8:

Tabel 8. Pembentukan Subset

\begin{tabular}{|c|c|}
\hline Item & Subset \\
\hline \multirow{2}{*}{$\mathrm{F}$} & $\{\mathrm{F}, \mathrm{A}\}$ \\
\cline { 2 - 3 } & $\{\mathrm{A}, \mathrm{F}\}$ \\
\hline \multirow{2}{*}{$\mathrm{M}$} & $\{\mathrm{M}, \mathrm{E}\}$ \\
\cline { 2 - 3 } & $\{\mathrm{E}, \mathrm{M}\}$ \\
\hline \multirow{3}{*}{$\mathrm{D}$} & $\{\mathrm{D}, \mathrm{C}\}$ \\
\cline { 2 - 3 } & $\{\mathrm{C}, \mathrm{D}\}$ \\
\cline { 2 - 3 } & $\{\mathrm{D}, \mathrm{E}\}$ \\
\cline { 2 - 3 } & $\{\mathrm{E}, \mathrm{D}\}$ \\
\hline \multirow{2}{*}{$\mathrm{B}$} & $\{\mathrm{B}, \mathrm{C}\}$ \\
\cline { 2 - 3 } & $\{\mathrm{C}, \mathrm{B}\}$ \\
\hline \multirow{2}{*}{$\mathrm{E}$} & $\{\mathrm{E}, \mathrm{C}\}$ \\
\cline { 2 - 3 } & $\{\mathrm{C}, \mathrm{E}\}$ \\
\hline
\end{tabular}


Setelah frequent pattern dan subset diketahui maka hasilrule dalam penentuan barang-barang yang memenuhi minimum confidence.

\section{Tabel 9.Paket Barang Dalam Bentuk} Awal

\begin{tabular}{|c|c|c|}
\hline Rule & Support & Confidence \\
\hline $\mathrm{D} \rightarrow \mathrm{C}$ & $20 \%$ & $100 \%$ \\
\hline $\mathrm{E} \rightarrow \mathrm{C}$ & $26.7 \%$ & $80 \%$ \\
\hline $\mathrm{C} \rightarrow \mathrm{E}$ & $26.7 \%$ & $57.1 \%$ \\
\hline
\end{tabular}

Setelah didapatkan bentuk awal paket barang, maka tahap selanjutnya adalah dilakukan proses lookup ke tabel barang. Hasil lookup ke tabel barang ditampilkan di tabel 10.berikut:

\section{Tabel 10.Hasil Pemaketan Rules}

\begin{tabular}{|c|l|}
\hline Rule & \multicolumn{1}{|c|}{ Paket Produk } \\
\hline $\mathrm{D} \rightarrow \mathrm{C}$ & $\begin{array}{l}\text { Jika konsumen membeli Kopi Mak } \\
\text { Angah Kecil, maka Gula Biasa 1kg } \\
\text { juga dibeli dengan confidence 100\% }\end{array}$ \\
\hline $\mathrm{E} \rightarrow \mathrm{C}$ & $\begin{array}{l}\text { Jika konsumen membeli Prendjak Teh } \\
\text { Celup 30, maka Gula Biasa 1 kg juga } \\
\text { dibeli dengan confidence } 80 \%\end{array}$ \\
\hline $\mathrm{C} \rightarrow \mathrm{E}$ & $\begin{array}{l}\text { Jika konsumen membeli Gula Biasa } \\
\text { Ikg, maka Prendjak Teh Celup 30 juga } \\
\text { dibeli dengan confidence 57.1\% }\end{array}$ \\
\hline
\end{tabular}

Dalam penentuan kombinasi barang yang akan dijual dalam bentuk paket pihak minimarket Ulfamart memiliki batasan khusus, yaitu :

1. Harga perpaket didapatkan dari pengurangan ke ribuan atau puluhribuan terdekat. Misalkan jumlah harga dari paket 1 sebesar Rp.33.200 maka akan dikurangi menjadi Rp. 30.000 .

2. Harga perpaket minimal sebesar Rp.20.000 dan maksimal Rp. 80.000 .

3. Jumlah barang yang dapat dipaketkan yaitu sebanyak 2 barang.

Dari batasan yang dimiliki oleh minimarket Ulfamart maka didapatkan rekomendasi paket sebagai berikut :
Tabel 11. Informasi paket

\begin{tabular}{|l|l|}
\hline Paket & $\begin{array}{c}\text { Paket } \\
\text { Item } \\
\text { Produk }\end{array}$ \\
\hline Paket & Kopi Mak \\
A & Angah \\
& Kecil, \\
& Gula \\
& Biasa Ikg. \\
\hline Paket & Prendjak \\
B & Teh Celup \\
& 30, Gula \\
& Biasa Ikg \\
\hline
\end{tabular}

Dari hasil pengolahan data ini kita dapat mengambil sebuah keputusan mana barang yang cocok untuk dijadikan sebuah paket penjualan barang. Jika ingin membuat paket penjualan barang dengan jumlah barang lebih dari dua maka data penjualan yang digunakan harus ditambahkan dan nilai support harus diturunkan agar rules yang didapatkan menghasilkan lebih dari dua buah kombinasi barang sehingga paket dapat dibentuk dengan jumlah item lebih banyak.

\section{KESIMPULAN DAN SARAN} Kesimpulan

1. Proses pelatihan dengan menggunakan 15 data sampel telah dianalisa berdasarkan data transaksi penjualan yang telah melewati tahapan preproccesing untuk mendapatkan kombinasi item produk yang dapat dijadikan sebuah paket hemat, di mana menghasilkan 5 rekomendasi paket hemat yang masingmasing paketnya sudah memenuhi batasan khusus dari pihak minimarket.

2. Algoritma

Fp-Growth memampatkan kumpulan data sebuah FPtree, memindai database dua kali, tidak menghasilkan item kandidat dalam proses penambangan, dan sangat efisien untuk penambangan.

3. Proses pengujian pertama dengan 
15data transaksi penjualan menghasilkan 8 rules yang memenuhi minimum support

sebesar 0,2 dan minimum confidence sebesar 0,5 . pengujian lanjut dengan data yang lebih banyak yaitu 60 data transaksi penjualan menghasilkan 7 rules yang memenuhi minimum support sebesar 0,1 dan minimum confidence sebesar 0,5

\section{Saran}

1. Jika ingin membuat paket penjualan barang dengan jumlah barang lebih dari dua maka data

penjualan yang digunakan harus ditambahkan dan nilai support

harus diturunkan agar rules yang didapatkan menghasilkan lebih dari dua buah kombinasi barang

sehingga paket dapat dibentuk dengan jumlah item lebih banyak.

2. Pada penelitian selanjutnya, untuk mendapatkan sebuah pola asosiasi dapat menggunakan algoritma lain agar bisa dilakukan perbandingan.

\section{REFERENSI}

Bi Dan, Thanh Thi et al (2015)."Implementasi Iterative Dichotomiser 3 Pada Data Kelulusan Mahasiswa S1 di Universitas Sebelas Maret".Jurnal ITSMART, Volume 4, Nomor 2, Desember 2015.

Dwi Meilani, Budanis dan Muhammad Asadulloh."Data Mining untuk Menggali Pola Mahasiswa Baru Menggunakan Metode Frequent Pattern Growth (Studi Kasus : Institut Teknologi Adhi Tama Surabaya)".Jurnal ITATS. Diambil dari: jurnal.itats.ac.id/wpcontent/.../11/jurnal-Budanis-kirimitats2.pdf (24 mei 2017)

Kurniawati, Anis "educational data mining (2014). (konsep dan penerapan)".Jurnal
Teknologi Informasi Vol. 4 No. 2, 2013

Marisa, Fitri (2013). "Pemetaan Pola Hubungan Program Studi Dengan Algoritma Apriori - Studi Kasus Spmu Unnes".Edu Komputika Journal, Volume 1, Nomor 1,2014

Mehay, Ankur et al (2013). "AnalyzeMarket Basket Data using FP-growth and Apriori Algorithm".International Journal on Recent and Innovation Trends in Computing and Communication, Volume: 1 Issue: 9, 2013

Neesha, Sharma dan Chander Kant Verma (2014).“Association Rule Mining: An Overview".IJCSC, Volume 5, Number 1, Maret 2014.

Nurani dan Hamdan Ghani (2017),

"Analisis Keterkaitan Data Transaksi Penjualan Buku Menggunakan Algoritma Apriori dan Algoritma Centroid Linkage Hierarchical Method (Clhm)".ILKOM Jurnal Ilmiah. Volume 9, Nomor 1, April 2017

Rahmat, Brilian(2017).“Implemetasi KMeans Clustering pada Rapidminer untuk Analisis Daerah Rawan Kecelakaan",Seminar Nasional Riset Kuantitatif Terapan 2017

Santony, Julius(2012)."Implementasi Data Mining dengan Metode Market Basket Analysis",Jurnal Teknologi Informasi \& Pendidikan. Vol. 5 No. 2

September 2012

Tampubolon, Kennedy et al, (2013).“Implementasi Data Mining Algoritma Apriori pada Sistem Persediaan Alat-Alat 
Kesehatan".Informasi dan Teknologi

Ilmiah (INTI). Volume

1, nomor 1, Oktober 2013

Venkatachari, Khavita \&Issac Davanbu

Chandrasekaran, (2016). "Market

Basket Analysis Using FP Growth

and Apriori Algorithm: A Case

Study of Mumbai Retail

Store".BVIMSR'S Journal of

Management Research, Vol. 8

Issue- $1:$ april : 2016

Yanto, Robi dan Riri Khoiriah, (2015)."Implementasi Data Mining dengan Metode Algoritma Apriori dalam Menentukan Pola Pembelian Obat". Citec Journal, Volume 2, Nomor 2, April 2015

Yi Zeng et al, (2015)."Research of Improved FP-Growth Algorithm in

Association Rules Mining".Hindawi

Publishing Corporation Scientific

Programming, Volume 2015 